\title{
Não me venha falar da malícia de toda mulher' . A sintaxe entre as protagonistas de Se eu fechar os olhos
}

\author{
Don't tell me about in malice off all woman. \\ The syntax between the protagonists of If $i$ close my eyes now
}

\author{
No vengas a hablarme de la malicia de toda mujer. \\ La sintaxis entre los protagonistas de Si cierro los ojos ahora
}

\author{
Aurora Almeida de Miranda Leão \\ Universidade Federal de Juiz de Fora - MG - Brasil \\ ORCID: https://orcid.org/0000-0002-4119-3596 \\ Endereço Currículo Plataforma Lattes: http://lattes.cnpq.br/2976603526773816 \\ E-mail: auroraleao@hotmail.com
}

\begin{abstract}
Resumo: O artigo analisa a narrativa da minissérie Se eu fechar os olhos agora (TV Globo, 2019), a partir da construção de suas principais personagens femininas. Elas são Isabel e a coadjuvante Adalgisa. É interessante observar que a obra é uma adaptação literária mas a personagem de maior ressonância junto à audiência foi justamente uma que não existia no romance original. Procuraremos analisar as principais características das duas, a forma como agem, falam e se vestem, como acontece a sintaxe entre elas e a forma como o subtexto revela a malícia como forma encontrada em ambas para tentar escapar do ambiente opressivo em que vivem. Faremos inicialmente uma análise da minissérie - com linguagem inspirada no cinema noir -, segundo a proposta de Motta (2013). Em seguida, partimos para o olhar detalhado dos seres ficcionais e vamos à metanarrativa, incluindo ideias de Luiz Carlos Maciel, Murray Smith e Ismail Xavier.
\end{abstract}

Palavras-chave: Narrativa. Personagens. Diegese. Feminismo. Cinema noir.

\begin{abstract}
This article analyzes the narrative of If $i$ close my eyes now (TV Globo, 2019) from building their main female characters. They are the protagonist Isabel and the supporting Adalgisa. The interesting the work is a literary adaptation but the character most resonant with the audience it was precisely one that didn't exist in the original novel. We will try to analyze the main characteristics of the two, the way to dress, but
\end{abstract}

\footnotetext{
${ }^{1}$ Versos da canção "Dom de iludir", de Caetano Veloso, lançada em 1982.

DOI: http://doi.org/10.14393/par-v6n1-2021-60545 - Paradoxos, Uberlândia, v. 6, n. 1, p. 160-175, jan./jun. $2021 \mid 160$
} 


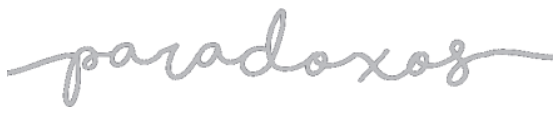

Não me venha falar da malícia

de toda mulher.

A sintaxe entre as protagonistas de

Se eu fechar os olhos

LEÃO, 2021

mostly the syntax between them. To do this, we will initially make an analysis of the miniseries - with language was inspired in film noir -, according to the proposal of Motta (2013). Then we depart for the detailed look of the fictional beings let's go to the metanarrative, including considerations of some theorists like Luiz Carlos Maciel, Murray Smith e Ismail Xavier.

Keywords: Narrative. Characters. Diegesis. Feminism. Film noir.

Resumen: El presente artículo investiga a narrativa de Si cierro los ojos ahora (TV GLOBO, 2019) desde la construcción de sus principales personajes femeninos. Ellas son la protagonista Isabel y la secundaria Adalgisa. El trabajo es una adaptación literaria pero el personaje de mayor resonancia con la audiencia era solo uno que no existía en la novela original.Intentaremos analizar las principales características de dos, como actúan, como hablan, como vesten pero principalmente la forma en que ocurre la sintaxis entre ellos. Inicialmente haremos una análisis de la miniserie - con lenguaje inspirada en el cine noir - según la propuesta de Motta (2013).Luego comenzamos a mirar a los seres de ficción en detalle y vayamos a la metanarrativa, incluidas las consideraciones de algunos teóricos como Maciel, Murray Smith y Ismail Xavier.

Palabras claves: Narrativa. Personajes. Diégesis. Feminismo. Cine noir.

\section{Introdução}

O tema deste artigo são duas personagens femininas da minissérie Se eu fechar os olhos agora, que teve ótima repercussão de público e crítica $^{2}$. Trata-se de uma adaptação do autor Ricardo Linhares para o romance homônimo do jornalista Edney Silvestre, prêmio Jabuti 2016. É a primeira minissérie produzida pelos Estúdios Globo e lançada primeiramente pelo serviço de streaming Net Now em 29 de agosto de 2018. Na plataforma digital Globoplay, a estreia foi em 8 de abril de 2019, e a exibição na TV Globo ocorreu de 15 a 30 do mesmo mês, no horário das $23 \mathrm{~h}$. A transposição para a teledramaturgia é assinada pelos diretores André Câmara e Joaquim Carneiro com direção artística de Carlos Manga Júnior.

\footnotetext{
${ }^{2}$ Ver crítica da obra em http://www.adorocinema.com/noticias/series/noticia-147808/. Acesso em 30 set 2019. DOI: http://doi.org/10.14393/par-v6n1-2021-60545 - Paradoxos, Uberlândia, v. 6, n. 1, p. 160-175, jan./jun. $2021 \mid 161$
} 


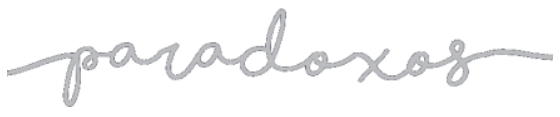

Não me venha falar da malícia

de toda mulher.

A sintaxe entre as protagonistas de

Se eu fechar os olhos

LEÃO, 2021

À época da estreia, Linhares (2019) declarou ter incluído personagens e situações novas ao romance original porque isso se fazia necessário para cativar o telespectador:

Você não pode fazer em televisão um programa de pequenas histórias, que em cada episódio tenha quatro ou cinco histórias que não se interliguem, que cada bloco seja de uma história diferente. Isso não funciona nem em televisão fechada nem em televisão aberta (LINHARES, 2019).

Partindo da proposta de análise crítica, a partir do que indica Luiz Gonzaga Motta (2013), e conforme desenvolvido em nossa dissertação de mestrado ${ }^{3}$, a investigação deve ter como fundamento a desconstrução do alicerce dramático para se compreender a produção de sentidos da narrativa, a partir de movimentos, os quais levarão ao entendimento da obra e as estratégias usadas para expor o discurso defendido pelos autores.

Sabe-se que na elaboração de um projeto audiovisual, todas as frações de sentido que se pretendem evidenciar através da narrativa devem fundamentar a diegese: o roteiro, a mise en scène $e^{4}$, filmar, selecionar os frames ${ }^{5}$ a serem usados, configurações de espaço x tempo, a montagem, a trilha sonora, a interpretação, enfim, as diversas etapas da construção audiovisual são essenciais para produzir o discurso.

Essa é uma premissa do cinema, conforme explica Ismail Xavier (2005), para quem um filme é "sempre um fato de linguagem, um discurso produzido e controlado, de diferentes formas, por uma fonte produtora”. (2005:14). Já Metz (1972) lembra que essa é, verdadeiramente, a intenção do filme, já que "a característica do cinema é transformar o mundo em discurso" (1972:137).

Os movimentos indicados por Motta (2013) são sete e abarcam desde a definição da intriga e a forma de desenvolvê-la; a essência da história e a incorporação de novos conflitos; a definição do clímax e o modo como ele será desvelado; o desenrolar das tramas secundárias; as estratégias argumentativas; a construção das personagens; os pontos de virada e as metanarrativas que compõem o cerne de toda diegese.

3 Ver dissertação da autora: "Sete movimentos à procura da narrativa". Disponível em http://repositorio.ufjf.br:8080/xmlui/handle/ufjf/9768. Acesso em 05 out 2019.

${ }^{4}$ Conceito desenvolvido na França, nos anos 50, que pode ser traduzido como encenação, e refere-se a tudo que envolve a construção de uma cena, seja em cinema ou teatro, e mesmo em televisão. Ver em https://www.meusdicionarios.com.br/mise-en-scene. Acesso em 03 out 2019.

5 Frame é cada uma das imagens fixas de um produto audiovisual. Disponível em https://www.tecmundo.com.br/video/10926-o-que-sao-frames-por-segundo-.htm. Acesso em 03 out 2019.

DOI: http://doi.org/10.14393/par-v6n1-2021-60545 - Paradoxos, Uberlândia, v. 6, n. 1, p. 160-175, jan./jun. 2021| 162 


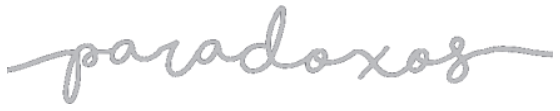

Não me venha falar da malícia

de toda mulher.

A sintaxe entre as protagonistas de

Se eu fechar os olhos

LEÃO, 2021

\section{A construção narrativa}

O ano é 1961 e a trama acontece na pequena cidade fluminense de São Miguel. Tudo começa com dois pré-adolescentes, Paulo Roberto (João Gabriel D'Aleluia) e Eduardo (Xande Valois), que saem do colégio e resolvem dar um passeio para tomar banho num riacho. Ali a conversa flui num clima de liberdade e sonho que convida o telespectador a aderir ao que parece ser uma história de leveza e nostalgia. Mas pouco depois, aquela harmonia tem um solavanco quando os dois garotos se deparam com o corpo de uma mulher mutilada, quase embaixo de uma pedra.

Figura 1: Thainá Duarte é Anita, pivô do crime na pacata cidade fluminense.

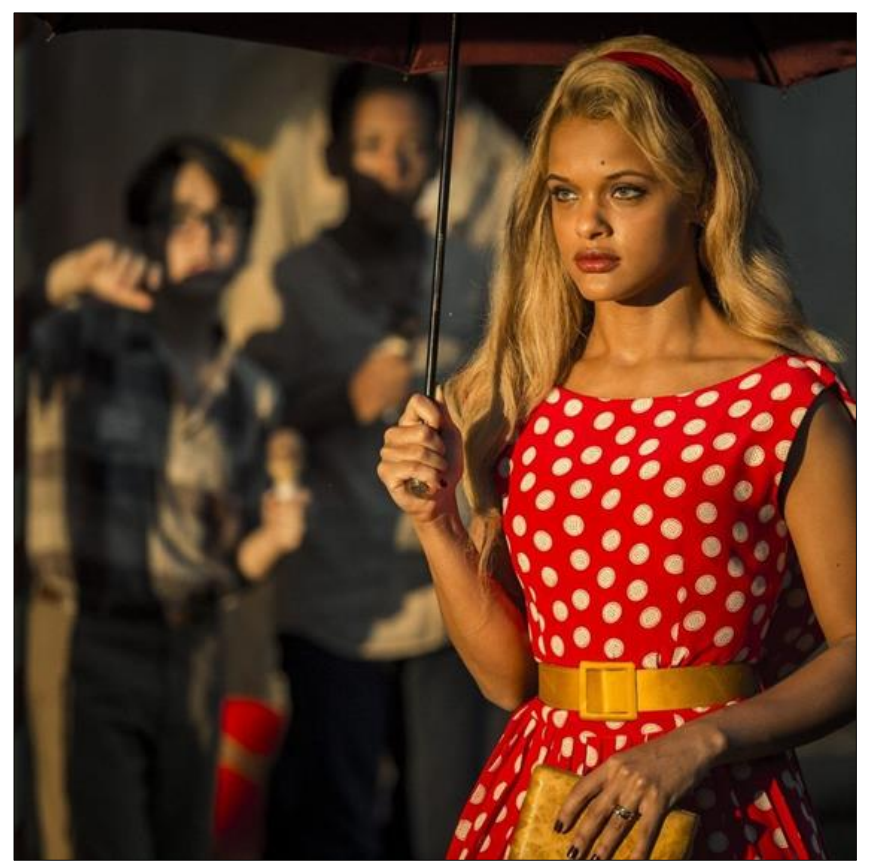

Fonte:TV Globo.

Aquele crime balança as estruturas da pacata cidade fluminense de São Miguel: acusados injustamente e quase presos, os garotos são favorecidos após o viúvo declarar-se culpado. Porém, todos quanto conheciam o senhor Francisco sabiam que ele seria incapaz de cometer um crime. Instado a fugir de uma investigação, o delegado decide arquivar o caso rapidamente antes que tome proporção nacional com o misterioso apoio do prefeito Adriano (Murilo Benício), da primeira-dama Isabel (Débora Falabella), do empresário Geraldo (Gabriel Braga Nunes), e da esposa deste, Adalgisa (Mariana Ximenes). 


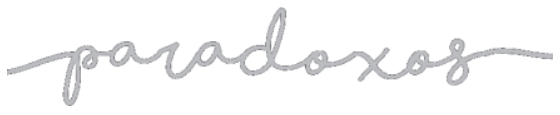

Não me venha falar da malícia

de toda mulher.

A sintaxe entre as protagonistas de

Se eu fechar os olhos

LEÃO, 2021

Intrigado com a revelação do dentista, Paulo resolve investigar o caso por conta própria, e convence o amigo Eduardo a aderir à missão. No percurso, conhecem um senhor misterioso que termina por ajudá-los. O enredo vai sendo desvelado e, a cada capítulo, o muito que vive recôndito debaixo do tapete da elite branca e escravocrata, fiel súdita das aparências, começa a ser evidenciado num painel de extrema sutileza no qual o escondido tem força de confissão.

No desenrolar de sua perquirição, os garotos acabam por descobrir o caso de Isabel com Renato (Enzo Romani), o alcoolismo de Adalgisa, os assédios de Antônio (Eike Duarte) às mulheres da cidade, o racismo praticado pelo bispo Tadeu (Jonas

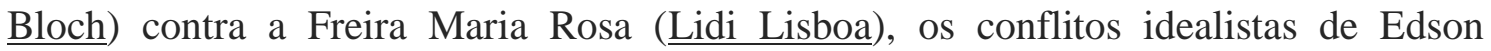
(Gabriel Falcão) contra os jogos políticos dos pais e a repreensão pública aos pensamentos feministas de Letícia (Lana Rhodes).

A história é contada por um narrador, que é o personagem Paulo já adulto, revivendo sua história a partir de memórias: suas lembranças são datilografadas e promovem reflexões que envolvem vários aspectos e personagens da pequena cidade fluminense nos anos de 1961, epicentro da trama. E o que vai sendo descoberto, a cada capítulo, é que todos na cidade tinham relações obscuras e dúbias com Anita, a vítima fatal. A trama acontece em 10 capítulos ou episódios e, para cada um, há um título. São eles: A Terra é azul?; A primeira vez; Queima de arquivo; $O$ irmão de Anita; Os inocentes; Laços de família; Os fantasmas de Ubiratan; A amante; A ponta do iceberg; e Os vivos e os mortos.

Todos esses títulos contribuem para afirmar a inspiração no thriller $^{6}$ policial e no cinema noir. Mais ainda, possuem uma rica simbologia e vão, a par e passo, trazendo ao cerne da narrativa a questão que é esteio para todo o discurso: as sombras nefastas e perversas que são o legado de anos de opressão às mulheres, a se refletirem numa sociedade hipócrita, conservadora, que vive de aparências e embasada num moralismo de isopor, que, ao primeiro embate, começa a ruir qual um castelo de cartas. Cada peça desenha sua frágil silhueta que, ao mais leve sinal de luz, desfaz-se no horizonte, tombando irremediavelmente frente às evidências.

\footnotetext{
${ }^{6}$ Gênero nascido do romance policial que está presente em filmes, telenovelas, jogos eletrônicos e narrativas audiovisuais de modo geral, cujo traço principal é o uso do suspense, da tensão e da excitação como principais elementos. Ver em https://brasil.elpais.com/brasil/2016/01/27/cultura/1453917653 876731.html. Acesso em 03 out 2019.
}

DOI: http://doi.org/10.14393/par-v6n1-2021-60545 - Paradoxos, Uberlândia, v. 6, n. 1, p. 160-175, jan./jun. 2021| 164 


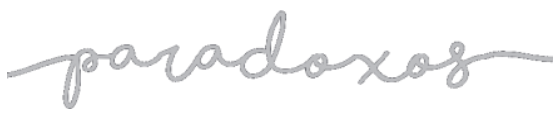

Não me venha falar da malícia

de toda mulher.

A sintaxe entre as protagonistas de

Se eu fechar os olhos

LEÃO, 2021

Figura 2: Isabel e Adalgisa: personagens com configurações distintas

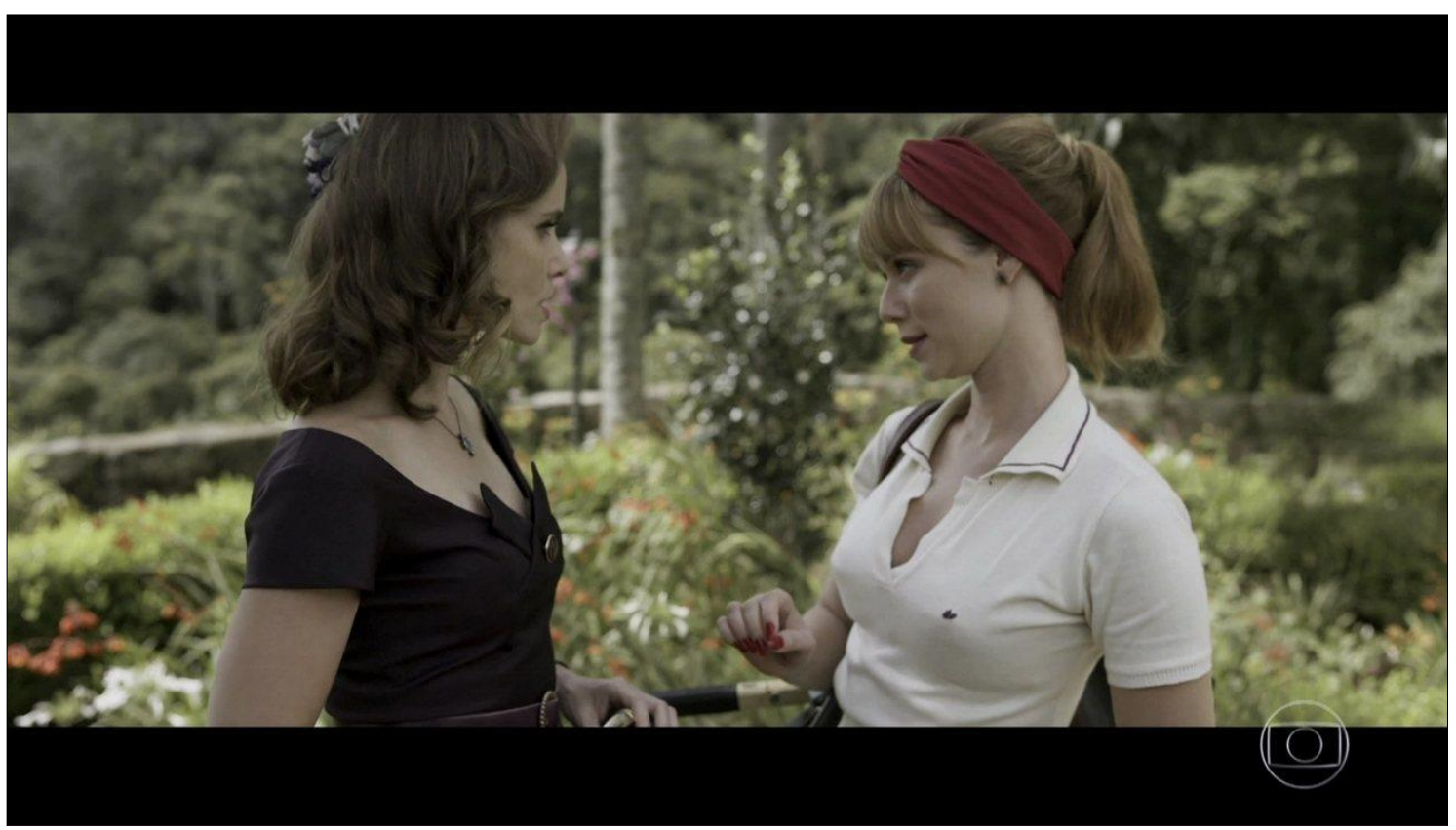

Fonte: TV Globo.

\section{As Personagens}

Entender a natureza dos personagens ajuda muito a compreensão da narrativa. Este aspecto é dos mais instigantes pois é a evidência do entrelaçamento ator-personagem, ou real-ficção, personificação-autoria: realça o caráter de humano de toda e qualquer personagem porque toda personagem representa um ser humano (MOTTA, p. 172):

Personagem é sempre uma criação, uma invenção do discurso narrativo, mesmo quando baseada em pessoas reais. [...] As personagens vivem e realizam as ações, são elementos-chave na projeção da estória e na identificação dos leitores com o que está sendo narrado: toda estória é intriga entre personagens [...] Não existe estória sem personagem, não "existe uma só narrativa no mundo sem personagens" (BARTHES, 1972, p. 41 apud MOTTA, p. 173).

Fica claro, portanto, que a personagem é o epicentro da narrativa: é a partir dela que se desenvolve a história, ela é o eixo do conflito em torno do qual gira toda a intriga. Já o roteirista Syd Field (1995) fala em alma, definindo a personagem 


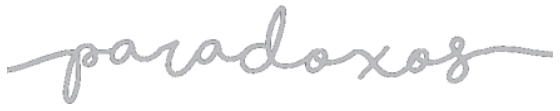

Não me venha falar da malícia

de toda mulher.

A sintaxe entre as protagonistas de

Se eu fechar os olhos

LEÃO, 2021

como "sistema nervoso da estória". O autor é taxativo: "ação é personagem e personagem é ação". Portanto, não é difícil entender que é através dos personagens que se chega a uma compreensão mais aprimorada do sentido da narrativa, ou podese até mesmo alcançar os vínculos da metanarrativa, conforme aponta MOTTA (2013). Nesse viés, tudo que você descobrir e entender sobre o personagem vai ajudar: do cabelo à música que ele gosta de ouvir, por exemplo.

Quanto à capacidade de autonomia de um personagem, Luiz Carlos Maciel (2017) recorre às palavras de Robert McKee: “O verdadeiro personagem só se expressa em um dilema de escolha. Como a pessoa age sob pressão é quem ela é - quanto maior a pressão, mais verdadeira e profunda é a escolha do personagem" (MACIEL, 2017, p.141).

O foco deste artigo são Isabel (Débora Falabella) e Adalgisa (Mariana Ximenes), personagens de alicerce menos óbvio, capazes de sinalizar um novo horizonte de possibilidade para as personagens femininas. Amigas e cúmplices, as duas tem personalidade e comportamentos distintos, cada uma com segredos bem escondidos. Ambas passam por percalços e levam uma vida de aparência, que o telespectador vai conhecendo pouco a pouco com o avançar da trama.

Figura 3: Débora Falabella como Isabel, a Primeira Dama da fictícia São Miguel.

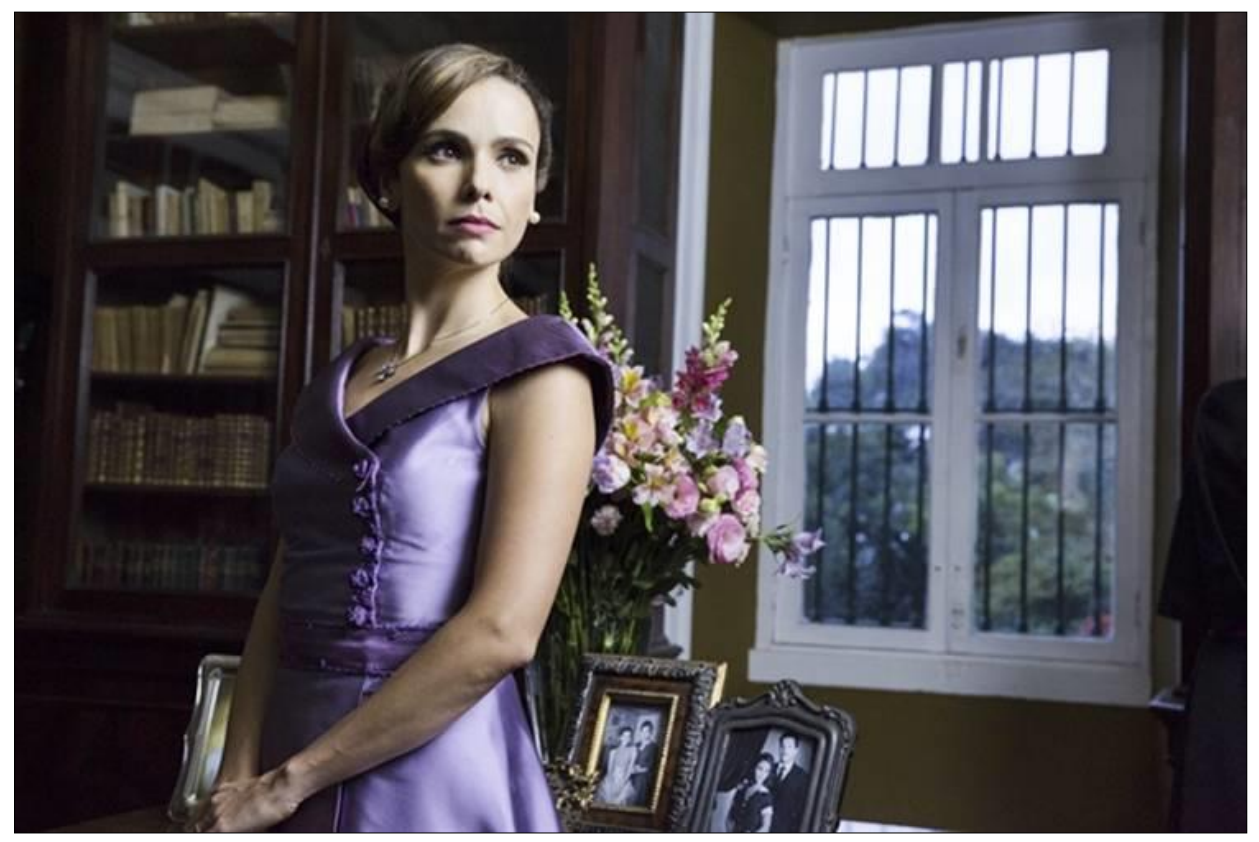

Fonte: TV Globo. 


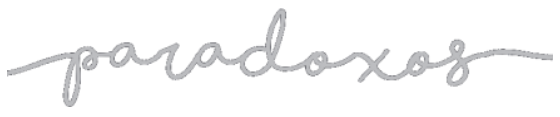

Não me venha falar da malícia

de toda mulher.

A sintaxe entre as protagonistas de

Se eu fechar os olhos

LEÃO, 2021

Isabel é elegante e tem gestos bem contidos. Típica dona de casa dos anos de 1960, é submissa ao marido, guardiã das tradições religiosas e do "bom comportamento" das filhas, mulher claramente oprimida e sem vida própria com um semblante denunciador de um cotidiano insípido e sem prazeres.

Adalgisa é o oposto e pode ser considerada um tipo de "loura fatal"7, embora com limites porque tem marido: sempre atrai olhares e curiosidade pelos trajes elegantes e exóticos que mostram suas curvas bem definidas. É casada com um rico empresário e tem um enteado com quem se dá muito bem. Este empresário, Geraldo, é também um personagem criado para a teleficção. Na história original, é apenas citado e teria apenas uma cena. Mas o autor Ricardo Linhares (2019) apostou na criação dele: o fez um empresário da elite, drogado, machista e bem interessado em se dar bem entrando para a política. Vejamos o que a imprensa dizia antes da estreia:

Adalgisa, interpretada por Mariana Ximenes, não existia no livro e já é uma das personagens preferidas do público, mesmo antes da estreia. Ela é uma mulher precursora e moderna, fala o que pensa, bebe, fuma e veste o que quer. É através dela que o autor irá abordar o machismo já que, mesmo sendo à frente do seu tempo, Adalgisa também é obrigada a se submeter às pressões sociais e mantém um casamento de aparências para conseguir sofrer menos na sociedade patriarcal em que vivia. (SERPA, 2019) ${ }^{8}$.

Foi assim que nasceu Adalgisa, figuradamente "da costela" de Geraldo. Loura, muito bonita e de olhos verdes, ela é uma ex-miss Distrito Federal, e tornou-se a personagem mais querida do público. Ao contrário da amiga primeiradama, Adalgisa é alegre, vivaz, está sempre fumando ou com um copo na mão, desperta atenção e comentários, diz umas frases irônicas ótimas ("A mulher não nasceu só pra ser a alegria do homem"), ainda que o marido esteja quase sempre por perto lhe vigiando os passos.

7 Mulher que desperta atenção e provoca olhares masculinos. Ver definição em https://www.dicionarioinformal.com.br/loira+fatal/. Acesso em 01 out 2019.

8 Ver matéria da revista Cláudia de abril de 2019: "Entenda Se Eu Fechar Os Olhos Agora, nova minissérie da Globo". Disponível em https://claudia.abril.com.br/noticias/entenda-se-eu-fechar-os-olhosagora-nova-minisserie-da-globo/. Acesso em 03 out 2019.

DOI: http://doi.org/10.14393/par-v6n1-2021-60545 - Paradoxos, Uberlândia, v. 6, n. 1, p. 160-175, jan./jun. 2021| 167 


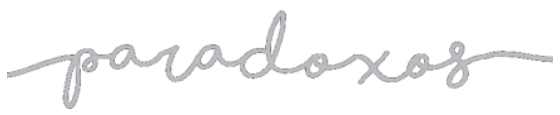

Não me venha falar da malícia

de toda mulher.

A sintaxe entre as protagonistas de

Se eu fechar os olhos

LEÃO, 2021

Figura 4: Mariana Ximenes interpreta Adalgisa, ex-miss, linda mas muito sofrida

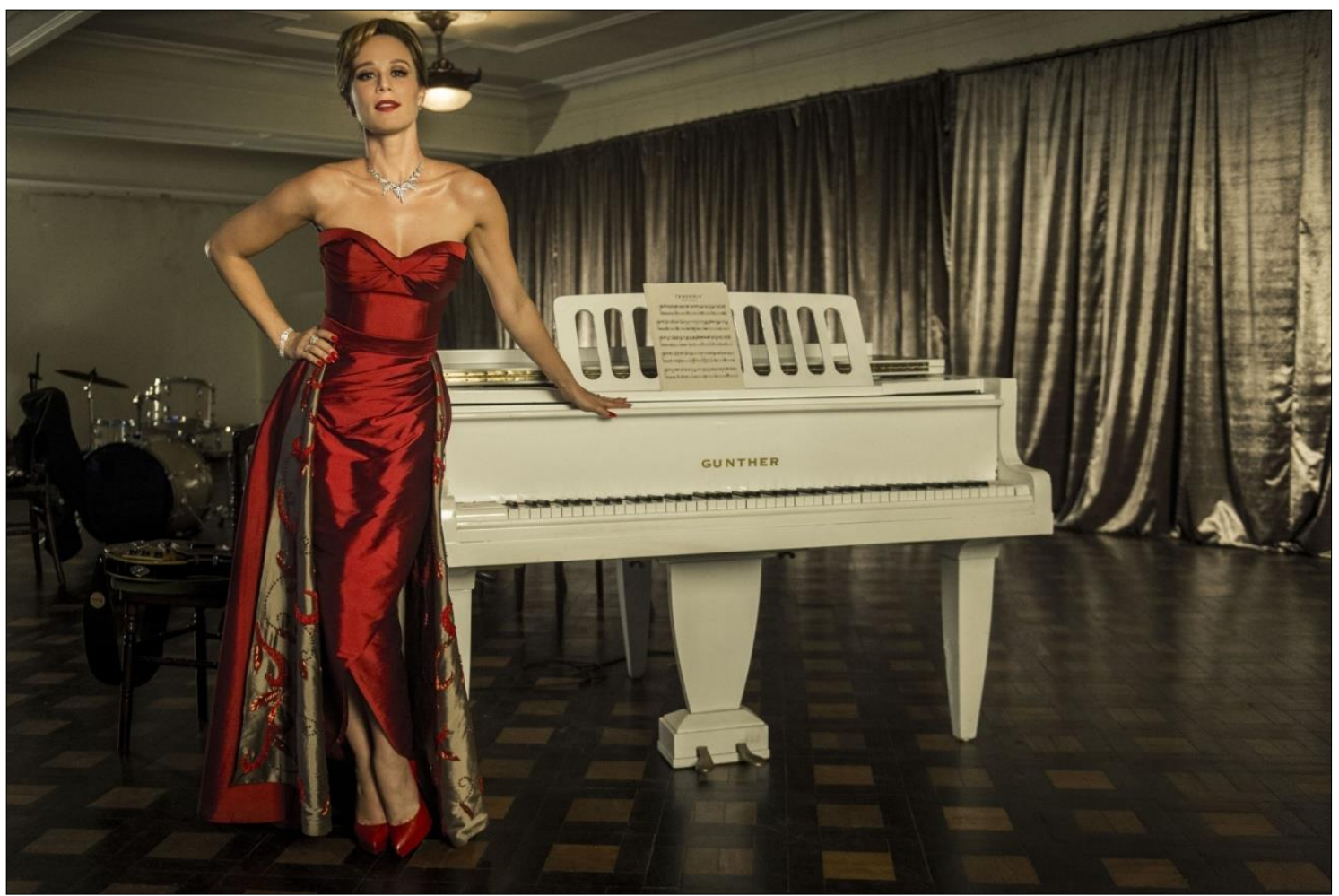

Fonte: TV Globo.

Sobre a construção das personagens, é interessante saber como o autor Ricardo Linhares criou sua adaptação, tendo recebido todo aval do escritor Edney Silvestre (2019). Ele criou actantes e fatos que não existiam no original, os quais, segundo ele, foram necessários "porque o livro de Edney é muito para um longa-metragem mas para a televisão precisava de mais elementos para causar empatia e emoção no público". 9

Ressaltamos que a "interferência" de Linhares foi prontamente acolhida por Silvestre, e não deixa de ter sido um risco: poderia não ter dado certo, ter descaracterizado a obra ou não ter funcionado com a audiência. Mas a acolhida ${ }^{10}$ de crítica e público asseguram o acerto das inclusões.

Tendo em vista que todo enredo deve ser portador de qualidades como verossimilhança, coerência, necessidade, convencionalização, universalidade, conforme

\footnotetext{
${ }^{9}$ Entrevista de Ricardo Linhares à jornalista Cristina Padiglione, colunista da Folha de São Paulo. Disponível em https://telepadi.folha.uol.com.br/autor-de-se-eu-fechar-os-olhos-agora-conta-como-olivro-chegou-tv/. Acesso em 22 set 2019.

10 Ver crítica do site Observatório do Cinema. Disponível em https://observatoriodocinema.bol.uol.com.br/criticas/criticas-de-series/2019/04/se-eu-fechar-os-olhosagora-critica-1a-temporada. Acesso em 03 out 2019.

DOI: http://doi.org/10.14393/par-v6n1-2021-60545 - Paradoxos, Uberlândia, v. 6, n. 1, p. 160-175, jan./jun. $2021 \mid 168$
} 


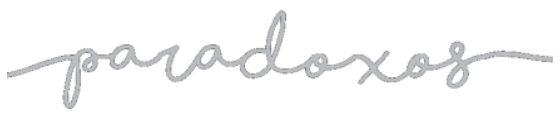

indica Vicente Ataíde (1974), vale a pena entender alguns motivos pelos quais a criação desses personagens - e, portanto, de situações que não estavam na história original - foi um risco e poderia não ter funcionado:

A ficção não precisa acompanhar os passos do senso comum ou da lógica; nem sequer da moral. Mas é preciso que, uma vez apresentada uma situação insólita, ilógica ou fantástica, contenha ela uma linguagem correspondente e esteja motivada por elos de causalidade necessária e segundo os demais ingredientes da narrativa. [...] O que é contrário às regras da arte não são as ações imorais, os caracteres perversos, o ilógico, o irracional, mas o que não se justifica pela força interna do próprio material exposto pelo artista (ATAÍDE, 1974: 28 e 29).

Personagens são, portanto, os elementos ativos de uma narrativa, "seres inventados pela imaginação", que vivem situações ficcionais num tempo e espaço delimitados, agindo de determinada maneira e por alguma razão, como explica Antônio Cândido (1976):

A personagem é um ser fictício, - expressão que soa como um paradoxo. De fato, como pode uma ficção ser? Como pode existir o que não existe? No entanto, a criação literária repousa sobre este paradoxo, e o problema da verossimilhança no romance depende desta possibilidade de um ser fictício, isto é, algo que, sendo uma criação de fantasia, comunica a impressão da mais lídima verdade existencial. Podemos dizer, portanto, que o romance se baseia, antes de mais nada, num certo tipo de relação entre o ser vivo e o ser fictício, manifestada. através da personagem, que é a concretização deste. (CÂNDIDO, 1976, p. 55).

Por outro lado, vejamos o que diz o professor Anatol Rosenfeld (2004), complementando a definição do colega: “É porém a personagem que com mais nitidez torna patente a ficção, e através dela a camada imaginária se adensa e se cristaliza” (ROSENFELD, 2004:21).

O professor Christian Pelegrini (2019) reforça esse raciocínio ao afirmar que a construção do personagem é fundamental para a qualidade da narrativa:

Os traços de personalidade vão determinar a gama de respostas que o personagem pode oferecer às situações dramáticas que se colocam diante dele (suas ações diante dos acontecimentos). São esses traços que o fazem agir dessa ou daquela forma, funcionando como o motor da ação dramática. Daí que personagens com poucos traços 
característicos compondo sua personalidade são simplistas - quando não, simplórios -e, por isso, previsíveis. (PELEGRINI, 2019) ${ }^{11}$.

Como independente da espécie, gênero ou quantidade em que se apresentam as personagens, a questão fundamental é identificar sua importância na estória narrada e compreender os conceitos por elas representados, vamos entender Isabel e Adalgisa. Para tanto, voltamos a Pelegrini, para reforçar que a constituição de um personagem é resultado dos traços de personalidade que o autor lhe faculta (2019):

Se a ação dramática é a forma como o personagem existe no modelo narrativo tradicional, compreendê-lo como algo além de um ente inerte da diegese é uma etapa imprescindível para entender o funcionamento da narrativa como um todo. A ação é função direta daquilo que o personagem é, do que acredita, do que deseja e do que teme. (PELEGRINI, 2019:3).

Adalgisa e Isabel apresentam programas narrativos próprios e suas trajetórias apresentam efeito cumulativo, ou seja, elas têm ações que precisam se desenvolver e passam por transformações relevantes ao longo da série por causa do muito submerso na exterioridade das cenas iniciais. Logo, a exposição dos acontecimentos em que elas estão envolvidas justifica-se. Como a dimensão temporal da minissérie apresenta grande economia (apenas 10 capítulos), a dimensão semântica é muito acentuada. E como o telespectador se vincula a essas personagens? Vejamos no próximo tópico.

\section{Engajamento, Aliança e Sintaxe}

Em seus estudos para tentar entender porquê certos personagens agradam e outros não, Murray Smith (1995) propõe um "sistema de engajamento" que atribui valores internos ao texto fílmico, organizado para situar constantemente os personagens em situações de relativa desejabilidade. Isso é o que leva à formação de uma hierarquia de preferências, simpatias e antipatias em relação a cada personagem. Basicamente, afirma que o personagem precisa ser bem construído para reagir ao que acontece na cena.

\footnotetext{
${ }^{11}$ Estudo repassado em sala de aula (primeiro semestre 2019) na disciplina "Narrativas em cinema e audiovisual", ministrada pelo Prof. Dr. Christian Pelegrini, no Instituto de Artes e Design da UFJF, em vias de ser publicado.

DOI: http://doi.org/10.14393/par-v6n1-2021-60545 - Paradoxos, Uberlândia, v. 6, n. 1, p. 160-175, jan./jun. $2021 \mid 170$
} 
Conhecido como "estrutura da simpatia", o sistema engloba três níveis: reconhecimento, alinhamento e aliança. Primeiramente, há a fase do reconhecimento do personagem na narrativa. Em seguida, o público se alinha a ele ao conhecer suas ações e motivações e, por fim, assume uma aliança com o personagem, reconhecendo suas visões morais e ideológicas.

Ter aliança ou alinhamento com um personagem indica um acesso à subjetividade desse ente fictício. Nesse tipo de aproximação público x personagem, registra-se uma convergência de aspectos morais. Mas para que isso aconteça é importante que o ambiente ou o cronotopo $^{12}$ não seja disfuncional, isto é, que favoreça a criação de um mundo adequado à inserção e desenvolvimento do personagem. No caso em análise, a opção pela estética noir $^{13}$ colabora decisivamente para criar uma ambiência soturna e enigmática, ideal para a construção das muitas nuances emocionais das personagens.

Outrossim, vamos pontuar lembrando alguns pontos que compõem o estilo consagrado por esse gênero do cinema: iluminação com excesso de contra-luz, narração off em primeira pessoa do personagem principal, presença do detetive privado e da mulher fatal, narrativa centrada na perseguição policial, e abordagem das personagens priorizando o aspecto psicológico. Todos esses elementos próprios da história inspirada nos cânones do cinema noir estão presentes em Se eu fechar os olhos agora. Vejamos então como se dá a aproximação do telespectador com as duas personagens da minissérie, tendo em vista elas são parte de uma ambiência noir e carregam muito mistério, o que as torna personagens complexas, tridimensionais (PELEGRINI, 2019), e qual a sintaxe que se verifica entre elas.

A série não conta a história de uma mudança de atitude das personagens, mas vai revelando, um pouco a cada capítulo, um lado recôndito de cada uma. As personagens, embora oprimidas e submissas aos maridos, não tem uma composição que reforce o estereótipo da mulher frágil e emotiva. São dissimuladas, mas apesar da opressão imposta pela sociedade atrasada, opressora e machista, fazem o que

12 Conceito criado pelo teórico russo Mikhail Bakhtin, é uma composição das palavras gregas cronos: tempo e topo: lugar.É usado para tratar da relação espaço-tempo no âmbito literário.Ver em http://ernaldina.blogspot.com/2013/06/cronotopo-algumas-reflexoes.html. Acesso em 03 out 2019.

13 Palavra francesa que significa a cor preta ou simplesmente negro. Ver em https://www.collinsdictionary.com/pt/dictionary/english/noir. Acesso em 03 out 2019.

DOI: http://doi.org/10.14393/par-v6n1-2021-60545 - Paradoxos, Uberlândia, v. 6, n. 1, p. 160-175, jan./jun. $2021 \mid 171$ 


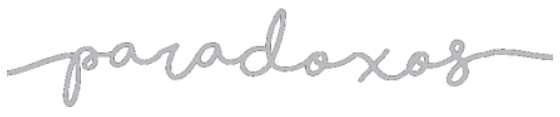

Não me venha falar da malícia

de toda mulher.

A sintaxe entre as protagonistas de

Se eu fechar os olhos

LEÃO, 2021

lhes apetece, quando longe dos olhares de censura. Essa configuração é claramente no intuito de promover uma dialogia (BAKHTIN, 1997) com a chamada segunda onda feminista mundial ${ }^{14}$, a qual apontava na década de 1960 seus primeiros passos no Brasil. A questão de gênero, aliás, tem nas duas um interessante foco para discussão sobre a questão do feminismo ${ }^{15}$, indo ao encontro da proposta de análise pela perspectiva de gênero (SCOTT, 1989).

Isabel e Adalgisa vivem em suas casas luxuosas e os maridos mantém financeiramente a vida de pompa delas. São quase vizinhas e a conversa delas quase sempre é sobre trivialidades ou como lidar com o sexo oposto. Isabel (Débora Falabella) é contida nas ações e seu figurino revela essa adesão ao formato de mulher bem casada imposto socialmente em décadas de predomínio do patriarcado. Não é, aparentemente, uma mulher que desperte nenhuma curiosidade nem desconfiança por qualquer traço de sua personalidade social, digamos assim.

Adalgisa (Mariana Ximenes) funciona noutra frequência: chama atenção pela beleza, pelos trajes e pelo modo de ser e falar, sempre alegre e disposta para a celebração. Desperta curiosidade também por ser ex-miss Distrito Federal, elegante e bonita, protótipo da mulher fatal que sempre habita o gênero noir. Exímia em frases desconcertantes, sempre na ponta da língua: "Só um adúltero trata bem a mulher... pra aliviar a culpa", diz ela à amiga no capítulo 2, quase final da cena aos 32'15". A amiga responde: “Adriano é tão munheca de samambaia que nem mesada me dá", e Adalgisa retruca: "Marido canguinha é o fim da picada ! Afinal, a única função do homem é sustentar a mulher”. Noutra cena, pergunta: “Que espécie exótica de mulher é você que nunca mentiu para o marido ?"Aliás, veremos que o discurso nos leva a confirmar o que pregava um dos principais slogans do feminismo, "o pessoal é político".

Em síntese, Adalgisa e Isabel são mulheres bem representativas do modo como viviam mulheres da elite brasileira nos anos de 1960, brancas, "domesticadas" e bem casadas. A exposição que a autoria lhes dá se justifica diegeticamente porque elas estão como estão para funcionar como contraponto ao discurso machista que a metanarrativa da obra condena. Viviam em palacetes sob aparências, fingindo-se

\footnotetext{
14 Ver em https://medium.com/qg-feminista/o-que-s\%C3\%A3o-as-ondas-do-feminismo-eeed092dae3a. Acesso em 03 out 2019.

15 Ver sobre as chamadas "ondas do feminismo" em https://medium.com/qg-feminista/o-que-são-asondas-do-feminismo-eeed092dae 3 a. Acesso em 04 out 2019.

DOI: http://doi.org/10.14393/par-v6n1-2021-60545 - Paradoxos, Uberlândia, v. 6, n. 1, p. 160-175, jan./jun. 2021| 172
} 


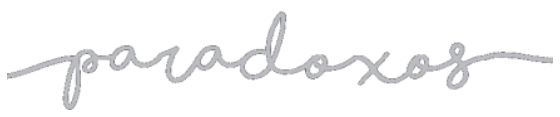

Não me venha falar da malícia

de toda mulher.

A sintaxe entre as protagonistas de

Se eu fechar os olhos

LEÃO, 2021

satisfeitas e felizes, mas carregando um sofrimento interior e uma tristeza que se expressa no olhar e nas lágrimas quando estão sozinhas.

É isso o que as une de modo inconteste, e o fato de ambas terem um segredo muito grande ligado à sexualidade, ao qual o telespectador só vai conhecer integralmente no capítulo final. Ambas tem peso decisivo no desenvolvimento do enredo: tudo gira em torno delas. Outrossim, o desenrolar da narrativa vai aos poucos nos revelando que são elas as principais envolvidas no crime que aniquila Anita - a jovem negra e motivo de machismo torpe -, e que as duas usavam o artifício da malícia e da dissimulação para exercer seus caprichos sexuais.

À propósito, recorremos à Antônio Candido (1995, p.53) para ressaltar que "o enredo existe através dos personagens; os personagens vivem no enredo". Portanto, se o personagem é o ente principal da ação - "sem ação não há personagem e sem personagem não há história”, como diz Syd Fieldman (1995) -, é sobretudo através deles que se conhece a autoria do discurso. São as personagens que representam o ethos da teleficção, acrescidos naturalmente pelo contexto da diegese e toda a mise-ènscene $^{16}$, como bem explica Christian Pelegrini (2019):

Se a ação dramática é a forma como o personagem existe no modelo narrativo tradicional, compreendê-lo como algo além de um ente inerte da diegese é uma etapa imprescindível para entender o funcionamento da narrativa como um todo. A ação é função direta daquilo que o personagem é, do que acredita, do que deseja e do que teme. (PELEGRINI, 2019, p 03).

No caso ficcional em estudo, os personagens são construídos com eficácia a partir de sua coerência e motivação para chegar ao ápice da narrativa, e são todos eles, não apenas as duas personagens femininas analisadas, confirmando o que diz Maciel (2017) sobre a proficuidade do bom desfecho:

O clímax é o destino final do roteiro, o ponto de chegada de sua trajetória. Ele determina o caminho que deve ser percorrido para alcançá-lo. Por isso, o roteiro deve ser construído para chegar ao clímax. O que acontece no clímax revela a solução encontrada para o conflito dramático e envolve, por isso, uma interpretação da realidade.

\footnotetext{
${ }^{16}$ É o processo que envolve a construção da cena com tudo aquilo que aparece no enquadramento, como por exemplo: atores, iluminação, decoração, adereços, figurino, etc. Ver em https://www.significados.com.br/mise-en-scene/. Acesso em 07/jul/2019.
} 


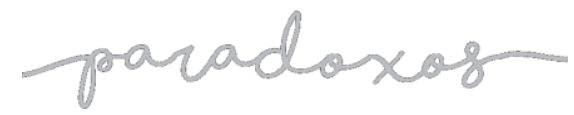

Não me venha falar da malícia

de toda mulher.

A sintaxe entre as protagonistas de

Se eu fechar os olhos

LEÃO, 2021

O clímax determina a forma e o conteúdo, pois tem o poder de introjetá-lo no espectador (MACIEL, 2017, p. 46).

Logo, se isso está bem definido, os personagens ganham porque podem ser construídos seguindo o princípio da motivação e da coerência, o que os nutre da possibilidade de serem críveis e, portanto, ganharem adesão e cumplicidade do público.

Figura 5: Imagem original de abertura da minissérie.

\section{Se eufechar os uthos agara}

(O) Se Eu Fechar Os Olhos Agora

Fonte: TV Globo.

\section{Considerações finais}

Pelo que podemos identificar na narrativa da minissérie "Se eu fechar os olhos agora", acreditamos que sua construção reafirma a importância de um texto bem construído, seja na forma de romance ou de roteiro audiovisual, ao mesmo tempo em que é uma demonstração material de que livro e cinema são obras diversas e, como tal, precisam ser vistas e analisadas, como tão bem explica o professor e crítico Ismail Xavier.

Outrossim, nos parece muito claro que a metanarrativa implícita na obra é o repúdio evidente ao machismo e seus danos, que fragilizam e vitimizam a todos, não só às mulheres. De forma inteligente e sensível, autoria e direção constroem um discurso audiovisual rico em intertextualidades e se esmeram em cativar o telespectador com DOI: http://doi.org/10.14393/par-v6n1-2021-60545 - Paradoxos, Uberlândia, v. 6, n. 1, p. 160-175, jan./jun. $2021 \mid 174$ 


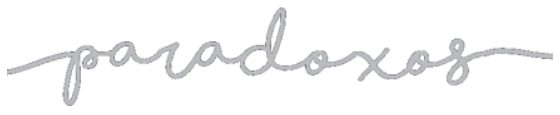

Não me venha falar da malícia de toda mulher. A sintaxe entre as protagonistas de Se eu fechar os olhos

LEÃO, 2021

uma trama recheada de suspense e mistério, com "ganchos" preciosos e um ritmo adequado ao que a narrativa quer desvelar. Ademais, ao valer-se dos cânones do thriller policial e do cinema noir, optam por uma forma inteligente de inserir-se na teledramaturgia, expressando o viés feminista da obra e definir sua diegese como um libelo contra toda forma de opressão, machismo e violência.

\section{Referências}

ATAÍDE, Vicente. A narrativa de ficção. São Paulo: Ed. Mc Graw-Hill do Brasil, 1974.

CANDIDO, Antônio. ROSENFELD, Anatol. PRADO, Décio de Almeida. GOMES, Paulo Emílio Salles. A personagem de ficção. São Paulo: Editora Perspectiva, 5ª edição, 1976.

FIELD, Syd. Manual de roteiro. Rio de Janeiro: Editora Objetiva, 1995.

MACIEL, Luiz Carlos. O poder do clímax - Fundamentos do roteiro de cinema e TV. São Paulo: editora Giostri, 2017.

METZ, Christian. A significação no cinema. São Paulo: Ed. Perspectiva, 2ª edição, 1972.

MOTTA, Luiz Gonzaga. A análise crítica da narrativa. Brasília: UNB, 2013.

ORTEGOSA, Marcia. Cinema noir: espelho e fotografia. São Paulo: Editora Annablume, 2010.

PELEGRINI, Christian. Aspectos do personagem no audiovisual: uma abordagem pela narratologia transmidiática. Juiz de Fora, 2019. No prelo.

SMITH, M. Engaging characters: Fiction, emotion, and the cinema. Oxford: Clarendon Press, 1995.

XAVIER, Ismail. O olhar e a cena. São Paulo: Cosac \& Naif, 2003.

XAVIER, Ismail. O discurso cinematográfico. São Paulo: editora Paz e Terra, 2005. 